\title{
COMENTARIOS EN TORNO A LA PICARESCA CERVANTINA EN ALEMANIA
}

Escribir sobre El Barroco y dentro de él sobre La novela picaresca, puede parecer, a la primera vista, algo carente de sentido por dos razones: por la abundancia de investigaciones que en torno a él existen y por la enorme calidad de éstas.

En nuestra exposición no pretendemos ni clarificar, ni ahondar en la línea de investigación existente, sino simplemente exponer una pequeña idea.

Hacer ahora una exhaustiva enumeración de toda la tradición picaresca barroca en Alemania, puede quizá resultar no muy atractivo para algunos lectores, conocedores en mucho de lo que aquí se va a tratar. Si bien y para mejor centrar el tema, daremos un pequeño repaso a la tradición barroca en el ámbito alemán; este pequeño repaso nos conducirá a la línea central y así deshilvanando la madeja llegar al meollo, al aspecto principal de nuestra investigación.

Según investigaciones de la talla de Gerhart Hoffmeister en el ámbito cultural alemán se comenzó a hablar de El Lazarillo de Tormes en el año 1614, cuando fue traducido al alemán por un humanista de Silesia ${ }^{1}$. Pero no sólo El Lazarillo influyó en la Literatura alemana y dio origen al nacimiento de un nuevo género, sino también el Guzmán de Alfarache. Y así siguiendo al Dr. Pérez Varas en su excelente trabajo de tesis doctoral "Notas a dos novelas de Johan Beer», diremos con él: "La novela pica-

${ }^{1}$ Gerhart Hoffmeister, Spanien und Deutschland, Grundlagen der Romanistik, Erich Schmidt Verlag. Berlin, 1976, p. 74. 
resca nace de la mimesis: procede de la imitación del "Lazarillo" y del "Guzmán" también» 2.

Es por tanto La novela picaresca alemana un género que nace de la copia de un género, y valga la redundancia, que se tiene por todos como auténticamente español y que vendría a corresponder con una etapa de florecimiento y de influencia en Europa de todo lo que constituía «lo español».

$\mathrm{Y}$ es que con El Lazarillo se siembra el germen de la novela realista en Europa. Su mismo autor nos dice:

«Yo por bien tengo que cosas tan señaladas y por ventura nunca oydas vengan a noticias de muchos y no se entierren en la sepultura del olvido, pues podría ser que alguno, que las lea, halle algo que le agrade y los que ahondaren tanto les deleyte* ${ }^{3}$.

Pero ese carácter realista se hace más despiadado y cruel en el género picaresco alemán y son circunstancias de variada índole las que contribuyeron a ello: "la tradición de los "Schwankbücher",..., la contaminación y promiscuidad de los géneros literarios y las circunstancias históricas" ${ }^{4}$. A esto habría que añadir la tendencia a la crudeza propia del artista germano, aspecto este que le diferencia bien del latino. Esta crudeza en la descripción de personajes y ambientes se verá más tarde reflejada en ese género de tradición tan germana como es El Expresionismo.

Con El Lazarillo surge un nuevo héroe, el pícaro, el antihéroe; La novela picaresca nace sencillamente como una reacción de oposición a los mitos épicos y sentimentales. Surge un nuevo hombre con sus sentimientos y sus adversas circunstancias.

Según Américo Castro en Hacia Cervantes se puede considerar la aparición de La novela picaresca, como: "consecuencia de la expresión del resentimiento social de la gente mísera contra las clases privilegiadas" 5 .

El pícaro hace alarde de ser el poseedor de un antilinaje. Se le concibe como un "alter ego" sobre el cual se descarga la vida invivible del converso.

Siguiendo a A. Parker - Los pícaros en la literatura. La novela picaresca en España y en Europa-, diremos que El Lazarillo es la novela precursora del género y que el prototipo es $E l$

${ }^{2}$ Feliciano Pérez Varas, «Notas a dos novelas de Johann Beer», en Filología Modema, 7-8, abril-agosto 1962 , p. 108.

${ }^{3}$ Francisco Rico, Lazarillo de Tormes. Edición de Francisco Rico. Madrid, Cátedra, «Letras Hispánicas», 1992. Prólogo.

4 Feliciano Pérez Varas, op. cit., p. 109.

s Américo Castro, Hacia Cervantes. Madrid, 1967, 3." edición, p. 118. 
Guzmán ${ }^{6}$. El Guzmán dio lugar en Alemania al Simplicisimus de Grimmelhausen (1669). Muchas novelas picarescas españolas fueron adaptadas al francés y traducidas al inglés y fueron decisivas en el nacimiento del realismo de ambos países, Inglaterra y Francia. Así no hay más que recordar a Lesage con su Gil Blas $(1715,1725$ y 1753). En Inglaterra la traducción hecha por Mabbe del Guzmán (1622) fue seguida por The English Rogue de Head y Kirkman $(1665,1668,1671)$. Las biografías reales o ficticias de sujetos de la clase criminal, que culminan con Defoe, se hicieron populares. "En pleno siglo XviII — nos dice Pérez Varashasta más allá del primer cuarto corren por Alemania junto al Robinsón inglés otros dos: el Niederländischer Robinson, que es el Kurtzweiliger Avanturier del holandés Heinsius, y el Spanischer Robinson, que no es otra cosa que el Gil Blas de Lesage. Como un eco dormido, por fin, reaparece solitario y anacrónico en 1743 el Simplizissimus redividus"?.

La novela picaresca alemana en lo que se refiere al campo de la traducción-adaptación, ya que no es posible separar a una de la otra, va ligado en sus comienzos a una zona, o mejor dicho a un país, Bayern; a la llegada de una orden religiosa, Los Jesuitas y a un nombre Aigidius Albertinus, cuya obra más importante novelada Der Landstörtzer: Gusman von Alfarache oder Picaro genannt (München, 1615), se puede considerar como un intento de adecuar la Novela picaresca al medio germano. A Albertinus se le considera el padre de la picaresca alemana, y en esta narración ha tomado elementos del Guzmán de Alfarache de Mateo Alemán y de una obra apócrifa. Pero la introducción del "Lazarillo" en Alemania data del año 1617 y fue dada a conocer en Ausburgo: Zwo kurtzweilige, lustige und lächerliche Historien. Die Erste von Lazarillo de Toremes, einem Spanier,... Die andere, von Isaac Winckelfelder, und Jobst von der Schneid. Su autor se llamaba Nicolas Ulenhart.

A mediados del s. XVII aparece en Nüremberg la segunda parte de El Lazarillo: Der Ander Theil Lazarilli von Tormes (Nürenberg, 1653 o 1656). El continuador de la genial obra era un español que vivía en París, por lo que ésta apareció en castellano y en francés. Por una serie de coincidencias, que ahora no vamos a tratar, la obra se le atribuye a Juan de Luna. Juan de Luna mantuvo lo castizo del lenguaje y el ataque a la Inquisición es aquí, si cabe, más abierto. Por todo ello y por su contenido se le considera la auténtica continuación del "Lazarillo".

- A. PARKer, Los pícaros en la Literatura. La novela picaresca en España y en Europa (1599-1753). Edimburgo, 1962, pp. 13 y ss.

7 Pérez Varas, op. cit., p. 108. 
La novela picaresca no es por tanto un género que surja por una serie de circunstancias socio-culturales, no es el producto final, ni el fiel reflejo de la conciencia de un país en decadencia, mísero y corrompido, y, por ello cuna de mendigos y maleantes. Los gremios de mendigos que nos presenta por ej. Cervantes en sus novelas, aparecen con múltiples variantes en otros países como Francia, Alemania, Italia e incluso Inglaterra, en donde la decadencia moral fue muy grande en tiempos de Isabel I. Y no olvidemos que Cervantes en su Don Quijote $(I, 22)$ considera el Lazarillo como paradigma del nuevo género picaresco.

Pero ¿cuáles son las características generales de El Lazarillo de Tormes? Esto es, de la novela precursora del género. Tres son las connotaciones que llaman a primera vista la atención del atento lector.

1) Las múltiples peripecias se articulan y encadenan entre sí. Los hechos pasados nunca desaparecen de la memoria del narrador y estos hechos van a condicionar el comportamiento posterior del protagonista.

2) El autor realiza siempre una selección de las aventuras y peripecias del protagonista y las supedita a sus propósitos.

3) Todas las peripecias que se narran, se alegan para justificar la situación presente en la que el protagonista se halla inmerso, y de la que tiene que rendir cuentas. "El Lazarillo -dice Tierno Galván - expresa una sociedad que hacia 1535 estaba en situación floreciente, sobre todo en la zona de las grandes ciudades mercantiles. El proletariado tenía conciencia de grupo explotado y de no estar comprometido con las aventuras e ideas de la clase dominante" ${ }^{8}$.

En El Lazarillo su protagonista, Lázaro, tiene auténtica conciencia de clase, y esto hace que se abra a una crítica universal. «Esto nos permite incluir dentro del género cualquier novela en la cual el proletariado, es decir, la clase o grupo explotado, marginado respecto de las conveniencias morales que rigen la convivencia, se ofrece como protagonista, con conciencia de clase y capacidad crítica" 9 .

Esta afirmación de Enrique Tierno Galván nos permite enlazar con el punto central de nuestra exposición crítica: « $¿$ Es $E l$ coloquio de los perros y la continuación que de esta obra realizó E. T. A. Hoffmann Nachricht von den neuesten Schicksalen des Hundes Berganza una novela picaresca? Carlos Blanco Aguinaga

${ }^{3}$ Enrioue Tierno Galvan, Sobre la novela picaresca $y$ otros escritos. Madrid, Tecnos, 1974, p. 51.

- Tierno Galvan, op. cit., p. 16. 
en su artículo "Cervantes y la Picaresca", pretende demostrar que Cervantes no escribió jamás novela picaresca; para ello aduce dos principios que para él son fundamentales: 1) «En la novela picaresca se nos cuenta siempre la historia de un trotamundos desheredado de la fortuna cuyo papel en la vida se reduce a ir satisfaciendo, de cualquier manera, sus necesidades más elementales".

Y continúa: «Y la segunda característica puramente formal en apariencia, pero imprescindible, es que las aventuras del pícaro se narran siempre en forma autobiográfica" ${ }^{10}$. De ahí que el diálogo que mantienen sea siempre fingido, pues la desconfianza del pícaro ante el resto de los hombres es total. "Soliloquio de Cervantes" denomina al Coloquio Laín Entralgo en La aventura de leer y lo divide en cuatro partes:

- Quiénes hablan.

- De qué hablan.

- Para qué y para quién hablan.

- Cómo hablan.

Pero en realidad son tres, ya que la última parte la deja en suspenso - yo no soy filósofo- dice disculpándose.

Del análisis de cada una de ellas deducimos que quienes hablan son dos perros, Berganza y Cipión. Berganza como testigo de la realidad que le rodea, es un espectador y nada más que un espectador, y Cipión perro "reflexivo y sentencioso", narran las andanzas y malandanzas del primero coreado por los adoctrinamientos y sentencias del segundo. Ambos, Cipión y Berganza, Berganza y Cipión, alma y cuerpo, cuerpo y alma, forman un todo que es fiel reflejo de su creador, que es Miguel de Cervantes. Tenemos entonces entre manos una narración autobiográfica en la que el narrador dialoga consigo mismo. «Cervantes, queriéndolo o no, nos ha confesado su personal visión del mundo en que vivió y buena parte de su personal modo de ser». Si aceptamos que la narración es autobiográfica y que su protagonista y autor es Cervantes, queda demostrado que no se trata de un coloquio, sino de un soliloquio que va dirigido, como continúa diciendo Laín: "A sus lectores, a los hombres todos, porque toda autobiografía, aunque sea fingida o alegórica, quiere ser una justificación de quien la escribe ante sus semejantes» ${ }^{11}$.

10 Carlos Blanco Aguinaga, «Cervantes y la Picaresca (Notas sobre dos tipos de realismo)», NRFH, 1957, p. 320.

1 Pedro Lafn Entralgo, «Coloquio de los perros, soliloquio de Cervantes», en La aventura de leer. Madrid, Espasa-Calpe, 1964, pp. 134-159. 
Esta opinión de la enorme importancia de lo autobiográfico dentro de la Novela picaresca, se ve también claramente manifestada por Claudio Guillén en «Hacia una definición de lo picaresco». "Una narración - dice este estupendo crítico, hijo del genial poeta Jorge Guillén-que no esté escrita en primera persona, no puede ser considerada, según mi opinión, como novela picaresca en sentido estricto del término" 12 .

Pero volvamos al punto central de nuestra discusión, ¿es el Coloquio de los perros una novela picaresca?

Desde finales del s. Xv venían utilizándose a los personajes de las clases más bajas, como una especie de proyectil para ser lanzados contra los abusos de los señores o de los eclesiásticos; así quienes carecían de dignidad social comenzaron a adquirir una posible significación literaria. Los temas del amor y del esfuerzo caballeresco fueron reemplazados por el tema del hambre, expresado en primera persona por quien lo padecía.

En Nachricht von den neuesten Schicksalen des Hundes Berganza (Noticia de las más recientes andaduras del perro Berganza) su autor E. T. A. Hoffmann (1776-1822) músico y escritor, quiere continuar las andanzas cervantinas y no lo oculta ni en el título, ni en la trama, los personajes cervantinos se han convertido en hoffmanianos. Aparece Cipión, como el inseparable amigo de Berganza y el episodio de las brujas se observa ahora desde la perspectiva romántica; E. T. A. Hoffman incluye incluso una nota aclaratoria a pie de página, en el comienzo del capítulo V (p. 79) ${ }^{13}$, y la página que él indica coincide con la edición de la traducción que D. W. Soltau, insigne romanista, realizara de las Novelas ejemplares de Miguel de Cervantes Saavedra. (Ver "La conversación de los dos perros, Cipión y Berganza» en las Narraciones de Cervantes, traducidas por Soltau, tercera parte p. 208). D. W. Soltau publicó su traducción en el año 1801.

En la novela su protagonista, Berganza (la obra está escrita en tono autobiográfico), aparece como un ser incomprendido y marginado dentro de la sociedad pequeño-burguesa de Bamberg, ciudad en la que está ambientada la novela. El célebre autor de Königsberg pasó unos años en esta ciudad como director del teatro de la capital.

Desde la marginación, se convierte Berganza en el gran censor social y literario, en parte por las vivencias personales que se derivaron de sus contactos con la pequeña burguesía ciuda-

12 Claudio Guillén, «Zur Frage der Begriffbestimmung des Pikaresken (1962)», en Pikarische Welt, Wege der Forschung CLXIII, pp. 375-396.

${ }^{13}$ E. T. A. HoffmanN, Fantasie und Nachtstücke. Winkler Verlag, München, 1964. 
dana y en parte también por la estrecha relación que mantuvo con el mundillo literario local. Hoffmann poseía un carácter muy abierto y era amigo de tertulias y francachelas.

¿Estamos, pues, ante una obra de matiz picaresco que continúa la tradición del género en época tardía?

Pérez Varas habla en su trabajo, ya anteriormente citado, refiriéndose a la disgregación del género picaresco en Alemania. Dice: «La crítica social, la narración premiosa de aventuras, la multiplicidad de escenarios, el realismo en sus varias manifestaciones, la forma autobiográfica, la problemática religiosa, el tópico del "niño mozo de muchos amos» en su forma pura o en situaciones análogas, todos estos elementos y muchos otros aparecen ahora en las novelas mezclados o en proporción varia, según la específica orientación del autor. Johann Beer, Daniel Speer, Eberhard Werner Happel, Johann Rismer, August Bohse, Johann Gottfried Schnabel, Christian Friedrich Hunold, entre otros, cultivan, según el gusto personal, cada uno o varios de los innumerables subgéneros en que se ha dividido por estas fechas la prosa narrativa" ${ }^{14}$.

Nachricht von den neuesten Schicksalen des Hundes Berganza se publica en el año 1814 y abre el segundo tomo de las Fantasiestücke (Obras fantásticas). De ella hubo una primera versión, en la que se acentúan aún más los sucesos acaecidos en Bamberg, principalmente en relación con su alumna de canto Julia Mark, de la que nuestro poeta se enamoró y transformó en la novela en Santa Cecilia, patrona de la música.

Si bien es imposible saber con exactitud cuándo leyó nuestro escritor la obra cervantina, sí podemos dar un período aproximativo de lectura el de 1811; para ello hemos especulado con los datos que ya conocemos: 1) Fecha de publicación de la traducción de Soltau, 2) toma de contacto con la familia Mark que se inicia en el otoño de 1809,3 ) experiencias teatrales en Bamberg, con autores tan importantes como Pedro Calderón de la Barca o Shakespeare, que van de 1809 a 1813. Lo que sí sabemos con exactitud es que de la "Nachricht..." hubo una primera versión en la que se acentuaban aún más los sucesos acaecidos en Bamberg, principalmente los alusivos a su alumna de canto. Si se nos permite sacar una deducción de las palabras de Maassen ${ }^{15}$, las Novelas ejemplares las leyó tras el rechazo de la primera versión y que la lectura de aquéllas, fue una feliz coin-

14 Pérez Varas, op. cit., p. 110.

15 Carl Georg Manssen, E. T. A. Hoffmann in Bamberg. Münchner Neuester Nachdruck, 10, 9, 1921, p. 8. 
cidencia que le ayudará a presentar de manera menos brutal las desastrosas vivencias bamberianas.

La novela no tuvo éxito, pues nos encontramos ante una obra desfasada, ante una obra picaresca. El artista toma conciencia de clase en el s. XIX. El pícaro muere y surge el artista con toda su problemática. La tradición picaresca no había muerto en el ámbito germano.

Blanca Ruiz 